\title{
Numerical Modeling of the Pipeline Uplift Mechanism in Clay
}

\author{
Kattar Abdelfateh ${ }^{1}$, Baheddi Mohamed ${ }^{2}$, Mohammed Yousif Fattah ${ }^{3}$ \\ ${ }^{1}$ Department of Civil Engineering, University of Batna2, Algeria. Email: fatehkattar123@gmail.com, \\ ${ }^{2}$ Department of Civil Engineering, University of Batna2, Algeria. Email: m.baheddi@ univ-batna2.dz, \\ ${ }^{3}$ Department of Civil Engineering, University of Technology - Iraq. Email: myf_1968@yahoo.com
}

(Received June 12, 2021; revised December 05, 2021)

\begin{abstract}
Buried pipelines are a vital infrastructure and are mainly used to transport energy carriers and other essential products. The pipes are generally buried in the upper layer of soil deposits and, therefore, are highly affected by different geo-environmental conditions. The various pathological cases recorded in the world are caused by the degradation of structures in contact with swelling soils, the fact that necessitates a full understanding and investigation of such a phenomenon. This paper presents a method for the pipeline behavior modeling based on the finite element analysis by using PLAXIS 3D software, aimed at the determination of the pipe bending moment, displacement over its length, and the evaluation of vertical stresses in soil under the pipe. A parametric study has been carried out to investigate the effect of the pipe burial depth and the soil cohesion. The finite-element results have been compared with experimental data from the literature. It was found that, unlike laboratory models, the numerical analysis can account for the internal pressure in the pipe and the depth of the pipe burial. The finite-element analysis showed that the presence of fluid pressure inside the pipe results in a decrease in the maximum swelling of the soil by about $95 \%$. The displacement of the pipe is considerably affected by the burial depth. The vertical stress at one end of the pipe can be greater than that at the other end in the case of a pipe under internal pressure, while in the case of an empty pipe, the values are very close at both ends. The numerical analysis shows that an increase in the pipe internal pressure leads to a decrease in its vertical displacement.
\end{abstract}

Key words: Clay; Swelling; Pipeline; Uplift; Finite Element Method

\section{Introduction}

Pipelines are a vital infrastructure and are mainly used to transport energy and other essential products. The pipes are generally buried in the upper layer of soil deposits and, therefore, are highly affected by different geo-environmental conditions.

Factors that lead to breaking of pipelines have been recognized as corrosion, internal pressure, traffic load, thermal stresses due to the environment temperature and

(C) 2021 Institute of Hydro-Engineering of the Polish Academy of Sciences. This is an open access article licensed under the Creative Commons Attribution-NonCommercial-NoDerivs License (http://creativecommons.org/licenses/by-nc-nd/4.0/). 
bending due to the forces generated by swelling/shrinking of clay (Makar et al 2001). Previous studies have showed that there is a clear relation between the increase in of the rate of pipeline breaking and the climate and the type of soil. For example, in 1996, Rajani and coworkers stated that pipeline rupture can be affected by seasonal climate, pipe diameter and its type. In addition, Gould (2011) studied the impact of seasonal variations of climatic conditions on failure rates of water cross linking pipelines in Australia. The seasonal variation in a number of pipe failure events took place because of excessive soil movements resulting from the shrinking and swelling of clay soils.

However, little research has been conducted to account for the mechanisms of expected failure of buried pipes in swelling soil. Even though, some authors (Pettibone and Howard 1976, Potter 1985, Shumulevich et al 1985, Sargand and Hazen 1998, McGrath 1998) have conducted large scale field laboratory analyses to investigate the distribution of soil pressure around the buried pipe. Whereas most of experimental work has been focused on backfilling materials, Kassiff and Zeitlen (1962), in their studies based on measuring field stresses, concluded that the elevated stresses induced by swelling result in a rupture of pipe. This type of failure has become a major concern for most of water and gas pipelines. Besides that, it can have harmful social environmental and economic influence on the community, and the cost of maintenance of pipe networks mounts to billions of dollars worldwide (WSAA 2008). Recently, Gallage et al (2012) studied the experimental laboratory piping buried in the expansive clay and noticed that the pipe undergoes considerable deformation as the soil swells with an increase in moisture content. Pipe analysis suggested by Rjeily and Khouri (2014) proved that the internal pressure induced in the deflected pipe under expansive soil was concentrated near the boundaries, where the deformation was blocked by the rigidity of the pipe under the non-active soil.

In the field of civil engineering, the phenomena of soil swelling and shrinkage are at the origin of many disorders for both structures built on the surface (buildings, superficial foundations, retaining structures, embankments, etc.) and for buried structures (tunnels, piles, pipelines, profound foundations, etc.). Examples of disorders related to the presence of swelling clay are reported by Philiponat (1991), Vandangeon (1992), Derriche et al (1999), Hachichi and Fleureau (1999), Djedid et al (2001) and Fattah et al (2017).

Expansive soils and rocks undergo volumetric changes upon wetting and drying, thereby resulting in soil heave and settlement problems. These characteristics cause considerable damage to pipes if not adequately taken into account. For swelling to take place, these soils must be initially unsaturated at some moisture content, if the unsaturated soil particles moisture content increases, the soil will swell. Opposite to that, if a decrease in moisture content took place, the soil would shrink (Al-Rawas and Goosen 2006).

The change in volume and the related soil movement were a conventional problem for structures buried in a swelling soil (Vu 2002). The buried pipelines used in 
transporting hydrocarbons, and various other liquids buried in swelling soils were as well influenced by shrinkage/swelling behavior (Gould et al 2009). As a result, the buried pipe has a high vulnerability to vertical movement which is known as upheaval buckling.

Consequently, it was obligatory to evaluate the uplift resistance to this movement. In this context; it has been many studies on prediction of uplift behavior. These were divided between theoretical work (Maltby and Calladine 1995, Martin and White 2012), full-scale testing (Eiksund et al 2013, Trautmann et al 1985), and geotechnical centrifuge testing (Ng and Springman 1994, Wang et al 2009).

Some authors attempted to numerically simulate the behavior of pipes in reactive soils. For instance, Rajeev and Kodikara (2011) have completed a numerical analysis of an experimental pipe buried in the ground, when there was a soil movement caused by an increase in water content. The pipe was suggested to behave as a linear-elastic material; meanwhile the soil was modeled as a non-linear material. The research estimated the soil movements' value that occurred during the flow of water. It was also proved that, in spite of the established effect of expansive soils on the behavior of pipe-lines, the study effort based on numerical modeling of the soil-pipe interaction behavior was limited (Rajeev and Kodikara 2011).

Therefore, the objective of this work is to numerically model the behavior of pipelines in swelling soils, in order to understand and analyze the effect of this type of soil on the vertical displacement of a pipeline, in order to determine the bending movement and the vertical stresses of soil under the pipe. This research is carried out for the case of a pipe-line buried in a swelling soil. More specifically, the analysis is conducted by applying a three-dimensional finite element model for the soil-pipe system. The research is focused on the empty and under-pressure pipe, and a parametric study is carried out based on the pipe burial depth and influence of soil cohesion. The latter will be utilized to get a comparison with laboratory results known from the literature.

\section{Pipeline Uplift Mechanisms}

The most critical location along a buried pipeline is at the crest of an over bend as illustrated in Figure 1. The available uplift resistance of the soil cover depends on the drainage conditions in the deforming soil, as well as on adherent conditions on the bottom face of the pipe. Three cases are possible; they are discussed below.

\subsection{Case 1 - Fully Undrained and Fully Bonded Conditions}

When soil underside a buried pipe is moving upward with the pipe due to adhesion, the failure mechanism resembles that of a reverse bearing capacity problem. The adhesion is generally provided by the negative excess pore water pressure generated underneath the pipe. Figure 2 illustrates a simple uplift mechanism which is similar to a basal stability problem as described by Bjerrum and Eide (1956). The constant volume 


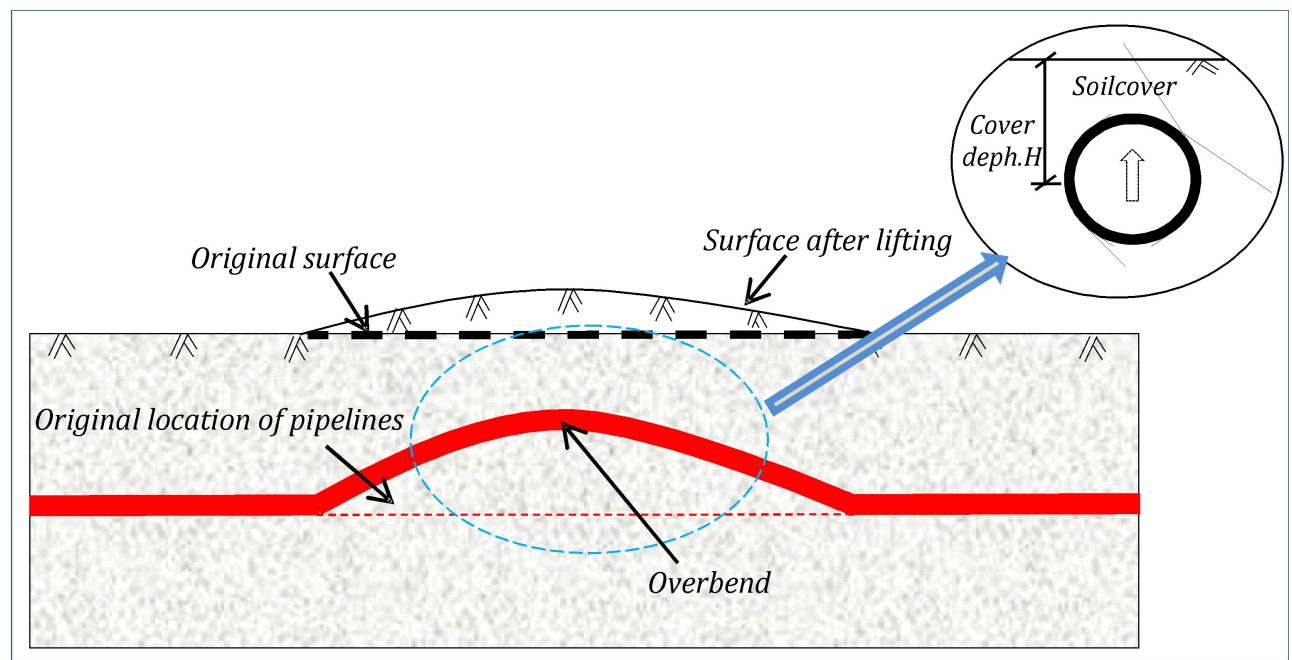

Fig. 1. Geometry of the pipe uplift problem

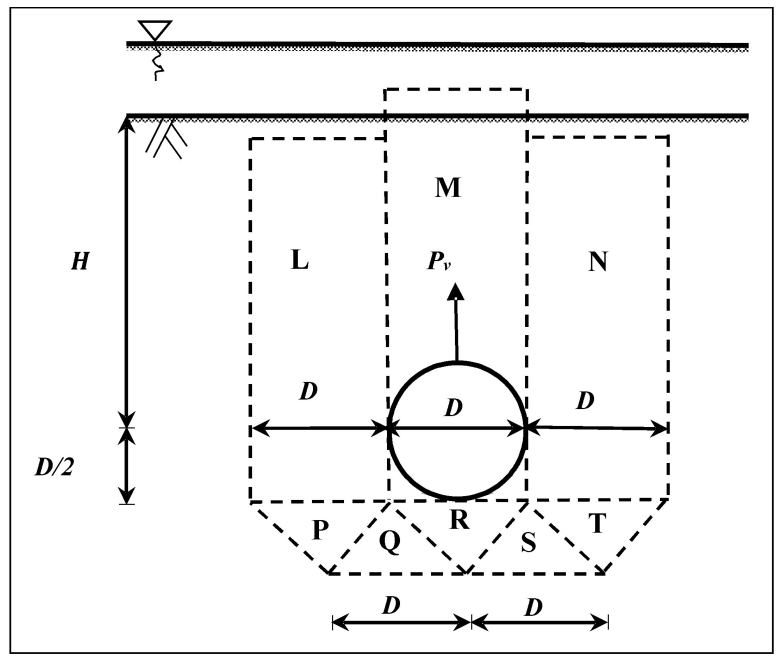

Fig. 2. Uplift mechanisms of a fully bonded buried pipe in clay under undrained conditions

condition ensures that the soil uplift above the pipe is compensated by the downward soil movement in soil masses $L$ and $N$. This indicates that there is no change in the potential energy in the whole mechanism. The uplift force per unit length of pipe $P_{v}$, which neglects the weight of the pipe, is given as follows:

$$
P_{v}=\left[4\left(H+\frac{D}{2}\right)+\frac{11 D}{\sqrt{3}}\right] S_{u, \text { ave }}=\left(\frac{4 H}{D}+8.35\right) S_{u, \text { ave }},
$$

where $H$ is the embedment depth of the pipe; $D$ is the diameter of the pipe, and $S_{u, \text { ave }}$ is an average undrained shear strength for the mechanism. This solution is used to 
illustrate an assumed mechanism, and in no way represents the upper bound estimate for the uplift resistance. It also shows that the uplift pressure increases with the embedment depth ratio $H / D$. Also, the failure mechanism becomes local with the increase of the latter.

The change in uplift mechanism with embedding depth was observed experimentally by uplift tests on buried plate anchors whose behavior was similar to that of buried pipes (Davie and Sutherland 1977). In the case of deep embedment depths, the mechanism is similar to a laterally moving pile with soil flowing around the circular structure.

Randolph and Houlsby (1984) presented plasticity solutions for the limiting pressure on a circular pile loaded laterally in cohesive soil, where they obtained exact solutions for piles with different roughness, but it was later discovered that a zone of negative plastic work was omitted in the upper bound solutions. The revised limit solutions indicate that the pile with a rough surface has a limiting pressure of about $11.9 s_{u}$. This means that the mechanism displays in Figure 2 is only more favorable than the flow around mechanism at small embedment.

The fully bonded condition in this case can also occur in the absence of adhesion as long as the embedment depth is deep sufficient. The confining pressure causes the soil to move around the pipe and push upward from the bottom of the pipe.

\subsection{Case 2 - Fully Uundrained and Unbonded Conditions}

When a gap forms under a buried pipe during uplift, the water pressure under the pipe will affect the uplift pressure (Figure 3a) in which the forces around an uplifting pipe are drawn. Two partial cases are considered.

In partial case 1 (Figure 3b), it is assumed that the water pressure condition below the pipe is hydrostatic. The total uplift force per unit length of pipe $P_{v, t o t a l}$, is given as follows:

$$
\begin{aligned}
& P_{v, \text { total }}=W_{S}+W_{P}+2 H S_{u, \text { ave }}-\gamma_{w}\left(A_{\text {soil }}+\frac{\pi D^{2}}{4}\right), \\
& P_{v, \text { total }}=W_{s}^{\prime}+W_{P}^{\prime}+2 H s_{u, \text { ave }},
\end{aligned}
$$

where $W_{s}$ is the total weight of the soil above, $W_{p}$ is the total weight of the pipe, $W_{s}^{\prime}$ is the effective weight of the soil above the pipe and $W_{p}^{\prime}$ is the effective weight of the pipe per unit length respectively, $\gamma_{w}$ is the unit weight of water, $A_{\text {soil }}$ is the surface of soil above the pipe, $H$ is the embedment depth and $H_{w}$ is the depth of water above soil surface.

In partial case 2, cavitation is assumed to occur below the pipe, leading to absolute zero pressure state below the pipe, as presented in Figure 3c. The value of absolute pressure is taken as $100 \mathrm{kPa}$. The total uplift force per unit length $P_{v, \text { total }}$ is given by the following relation: 


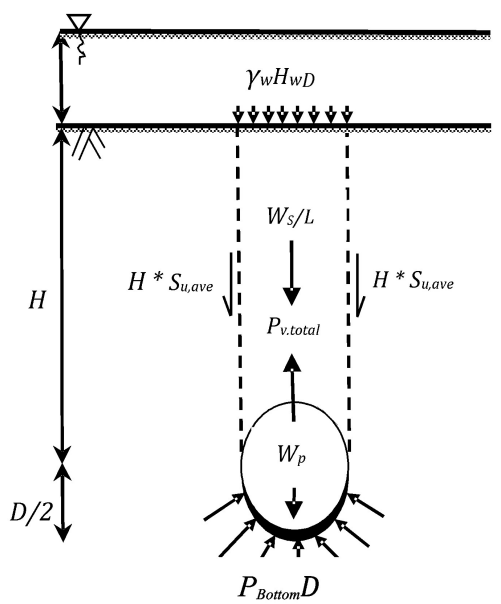

(a)

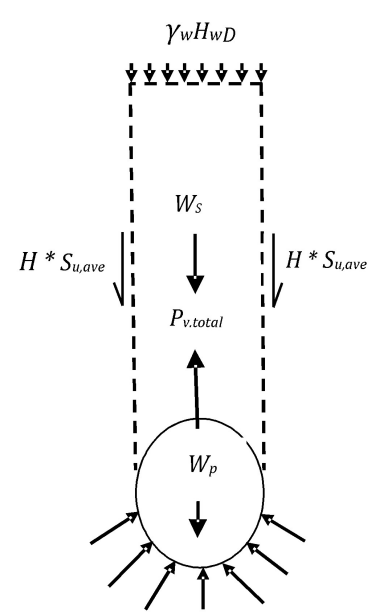

(b)

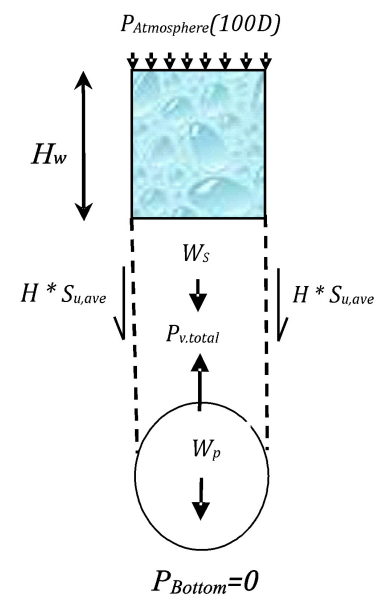

(c)

Fig. 3. Uplift mechanisms of an unbonded buried pipe in clay under undrained conditions: a) Free body diagram; b) Partial case 1 - Hydrostatic conditions; c) Partial case 2 - Cavitation occurs

$$
P_{v, \text { total }}=100 D+\gamma_{w} H_{w} D+W_{s}+W_{P}+2 H s_{u, a v e} .
$$

This case in the physical sense is logical, but is unlikely to occur in reality (Cheuk et al 2007).

\subsection{Case 3 - Fully Drained Conditions}

In the case of fully drained conditions, the total uplift resistance per unit length $P_{v . t o t a l}$ consists of the effective weight of the soil and the pipe, in addition to shear resistance along the failure surface, as illustrated in Figure 4 . The net uplift force per unit length $P_{v}$ is given by the following relation:

$$
P_{v}=P_{v, \text { total }}-W_{P}^{\prime}=W_{s}^{\prime}+2 H \tau_{\text {ave }}
$$

where $\tau_{\text {ave }}$ is the average drained shear resistance along the slip surface.

The probability of the occurrence of this case in clay is low due to the low permeability of the soil. Also, the mechanism illustrated in Figure 4 is specific to non-dilatant soil only (the dilation angle $\psi=0$ ). When the embedment depth sufficiently large, the soil flow around the periphery of the pipe resembles the situation described in case 1, even in the absence of any adhesion force underside the pipe under a fully drained condition. 


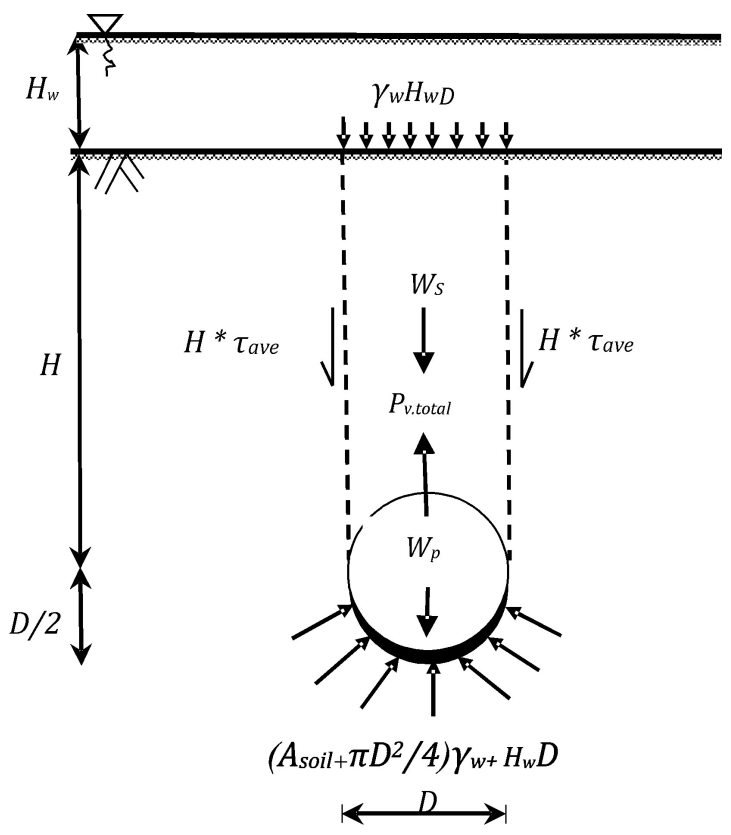

Fig. 4. Uplift mechanisms of a buried pipe in clay under fully drained conditions

Schaminée et al (1990) suggested that the uplift resistance of a soil cover could be non-dimensionalised to give an empirical uplift factor $\left(F_{u p}\right)$, which can be used to compare soil uplift resistance for different soil states and conditions.

$$
\begin{gathered}
\frac{P_{v}}{\gamma^{\prime} H D}=1+F_{u p} \frac{H}{D}, \\
F_{u p}=\frac{H}{D}\left(\frac{P_{v}}{\gamma^{\prime} H D}-1\right) .
\end{gathered}
$$

\section{Numerical Modeling}

\subsection{Model Description}

The model is spatially symmetric and consists of a soil mass with dimensions $(10 \times 8 \times 8) \mathrm{m}$ and an HDPE pipe buried in a homogenous layer of swelling clay buried at a depth $1.20 \mathrm{~m}$ below soil surface. The location of water table depth is at a level of $2.0 \mathrm{~m}$. This problem is analyzed using the Finite Element Method software PLAXIS 3D-2013. The main 3D finite element mesh soil elements consist of 10-node tetrahedral elements. Additionally, specific types of elements are used to simulate the structural behavior. Three-node bar elements are utilized for beams; these elements are compatible with the 3-node edge elements of a soil element. Moreover, 12 node interface elements are used to simulate soil-structure interaction behavior. 
The behavior of clay is modeled by adopting an elasto-plastic relation described by the undrained Mohr-Coulomb criterion.

The soil swelling is simulated by applying a swelling pressure (negative pressure) of $-600 \mathrm{kN} / \mathrm{m}^{2}$ to the soil mass. This value of swelling pressure was obtained previously from the free swell test of soil used. The swelling pressure was applied to the soil at the same value below and above the water table level. In reality, the rate at which expansive soil would normally swell depends on the position from the source of moisture and magnitude of over burden effective pressure. However, for simplification, in the analyses presented here, the swelling pressure is applied uniformly across the full depth of the soil mass. The material of the pipe-line is assumed to obey linear elastic behavior. The internal pressure in the pipe is simulated by a negative contract force of $-2 \%$ at nodes, due to the Plaxis 3D software not including the internal pressure in the pipe, where the circumferential deformation (contraction at nodes) of the pipe is given by the following relation:

$$
c=\frac{2 \pi r^{2} P}{D E e}
$$

where $C$ is the circumferential deformation of the pipe, $P$ is the fluid pressure in the pipe, $E$ is the elastic modulus of the pipe, $e$ is the wall thickness of the pipe, and $D, r$ is the internal diameter and radius of the pipe, respectively. The pressure in the pipe in physical units $(\mathrm{Pa})$ is $700000 \mathrm{~Pa}$. The model parameters adopted in the analysis are listed in Table 1.

Table 1. Material properties used in the numerical model

\begin{tabular}{|c|c|c|}
\hline Material & Property & Value \\
\hline \multirow{4}{*}{ Soil } & Saturated unit weight $\left(\mathrm{kN} / \mathrm{m}^{3}\right)$ & 22.60 \\
\cline { 2 - 3 } & Unsaturated volumic weight $\left(\mathrm{kN} / \mathrm{m}^{3}\right)$ & 21 \\
\cline { 2 - 3 } & Elastic modulus $\left(\mathrm{kN} / \mathrm{m}^{2}\right)$ & 7000 \\
\cline { 2 - 3 } & Cohesion $\left(\mathrm{kN} / \mathrm{m}^{2}\right)$ & 95 \\
\cline { 2 - 3 } & Poisson's ratio & 0.35 \\
\cline { 2 - 3 } & Angle of friction (Degree) & 20 \\
\hline \multirow{4}{*}{ Pipe } & Diameter (mm) & 200 \\
\cline { 2 - 3 } & Wall thickness $(\mathrm{mm})$ & 12 \\
\cline { 2 - 3 } & Elastic modulus $\left(\mathrm{kN} / \mathrm{m}^{2}\right)$ & 900000 \\
\cline { 2 - 3 } & Poisson's ratio & 0.30 \\
\hline
\end{tabular}

For boundary conditions, the base of the model was blocked in all directions, and the horizontal displacement was zero in the lateral faces of the soil mass, on $\mathrm{x}=0$ and $\mathrm{x}=8$ planes, and $\mathrm{y}=0$ and $\mathrm{y}=5$ planes. However, the pipe was considered fixed at two ends allowing for similar conditions. The average element size and the number of the 15-node triangular elements depend on the global coarseness's setting. Fine finite element mesh was chosen, as illustrated in Figure 5, which was proved to be the most appropriate and providing sufficient accuracy. The mesh consists of 35568 elements representing the soil domain, while 594 structural elements have been used to model 
the pipe. A contact condition without complete slip between the soil and the pipe is assumed at the soil-pipe interface. Plastic calculations and staged construction of the pipe are selected to determine the final uplift in the selected points.

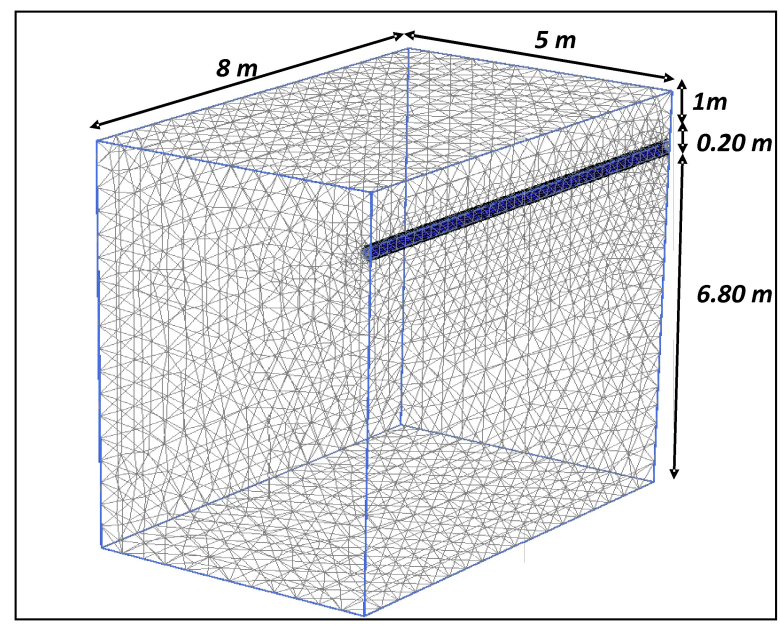

Fig. 5. Finite element mesh for soil - pipe system

\subsection{Results and Discussion}

For the buried pipes, the loads are generally classified into two broad categories: internal pressure and external loads. The interior pressure is calculated as hydrostatic pressure in addition to the surcharge pressure, while the external loads are considered to be caused by the soil external pressure.

Based on the numerical simulations, it has been shown that the swelling pressure resulting in the deformation of the soil mass is represented by a deformed net of soil-pipeline system model. The focus is on two kinds of deformation: shape deformation and interior deformation such as: 1 - mesh deformation, and 2 - the structural elements deformation.

The pipe vertical displacement, bending moments and vertical stresses below the pipe are the major outcome of this analysis. Figure 6 displays the deformed mesh for the cases of the empty pipe and pipe subjected to fluid pressure conditions. Figure 7 illustrates the vertical displacement zones in the soil around the pipe when it is either empty or under pressure. The positive values of displacement refer to swelling.

It can be seen in the plots that the application of the fluid pressure inside the buried pipe caused a decrease in the soil maximum swelling from $19 \mathrm{~mm}$ to less than $1 \mathrm{~mm}$.

Figure 8 displays the vectors of displacement of the soil flow surrounding the pipe. It is noticed that the movement of soil particles decreases when the internal pressure is applied inside the pipe. 


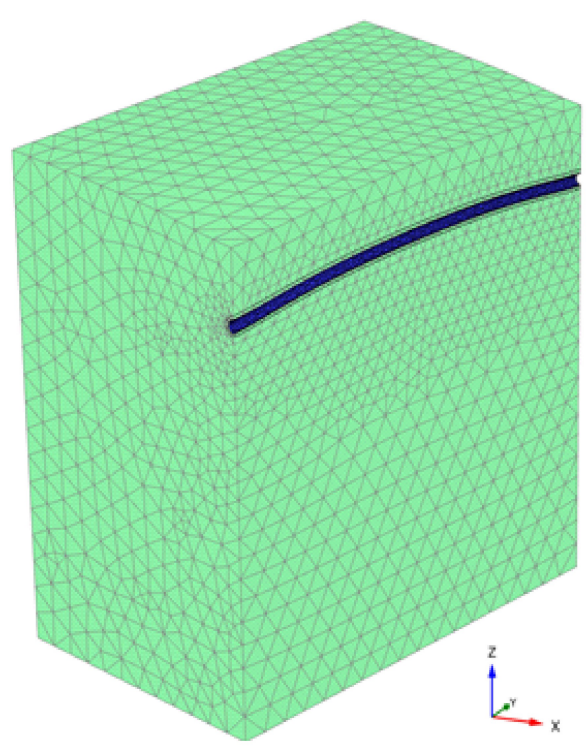

(a)

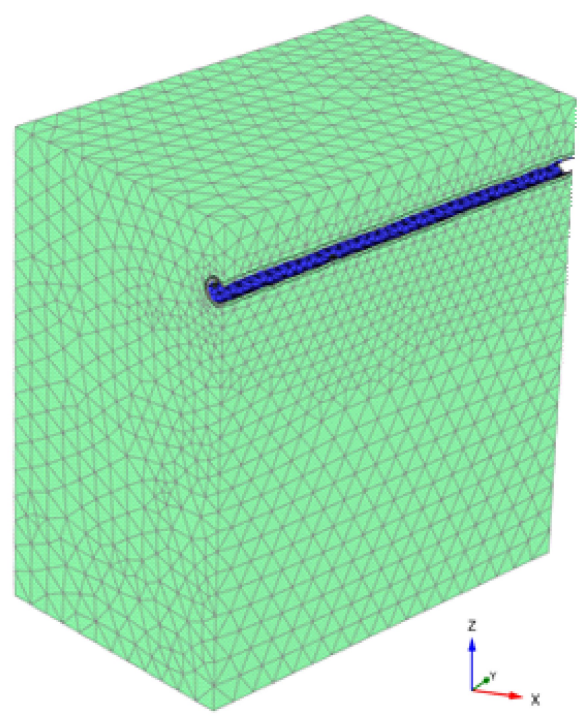

(b)

Fig. 6. Deformed mesh: (a) empty pipe, (b) pipe under pressure

Figure 9 displays the deformed shape of the soil - pipe system, indicating a considerable effect of the internal pressure inside the pipe.

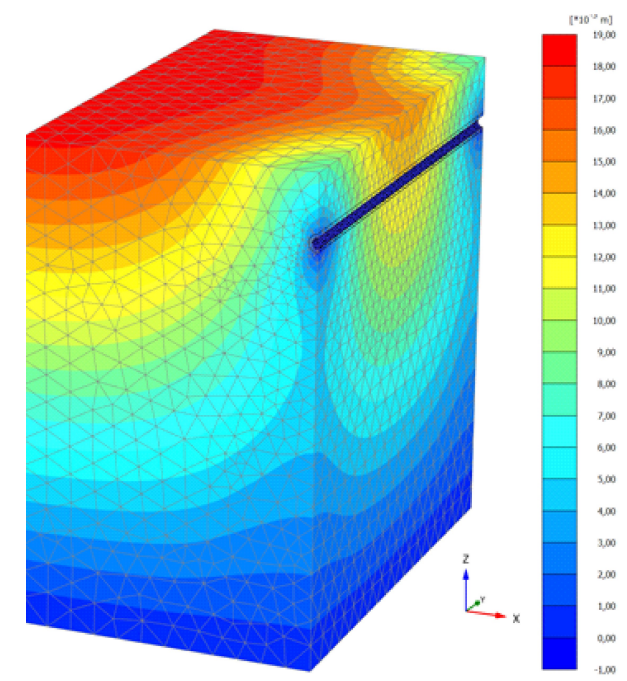

(a)

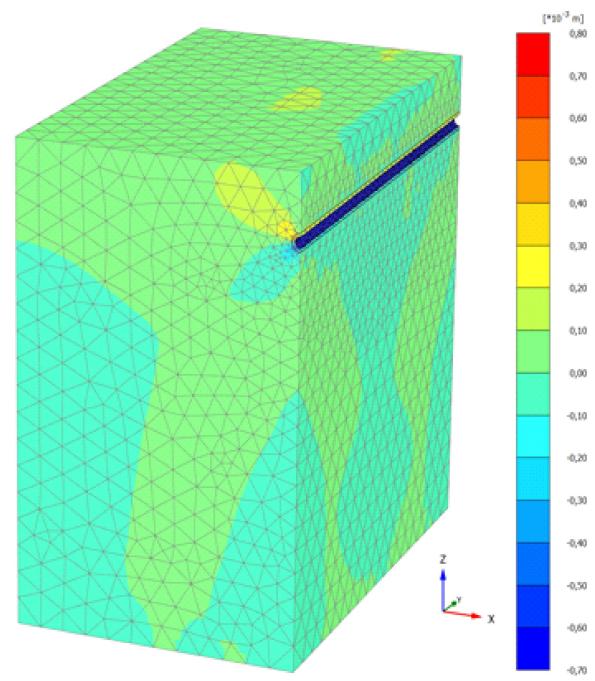

(b)

Fig. 7. Shading diagram of the vertical displacement (in meters) distribution resulting from the swelling of expansive soil: (a) empty pipe, (b) pipe under pressure 


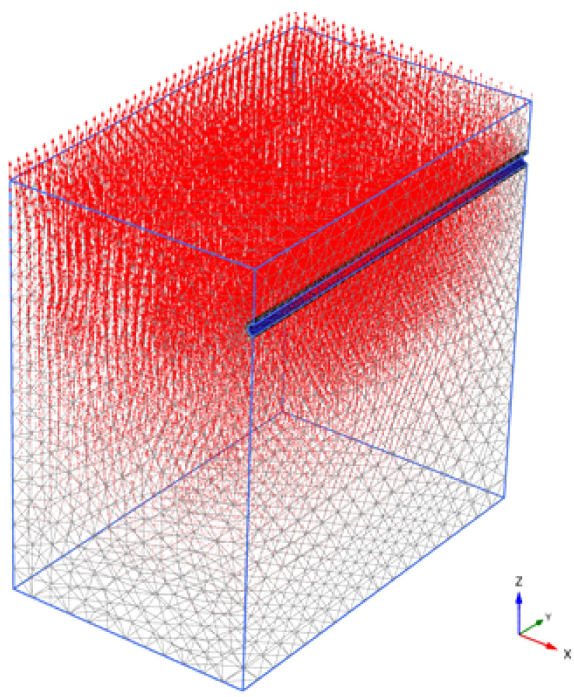

(a)

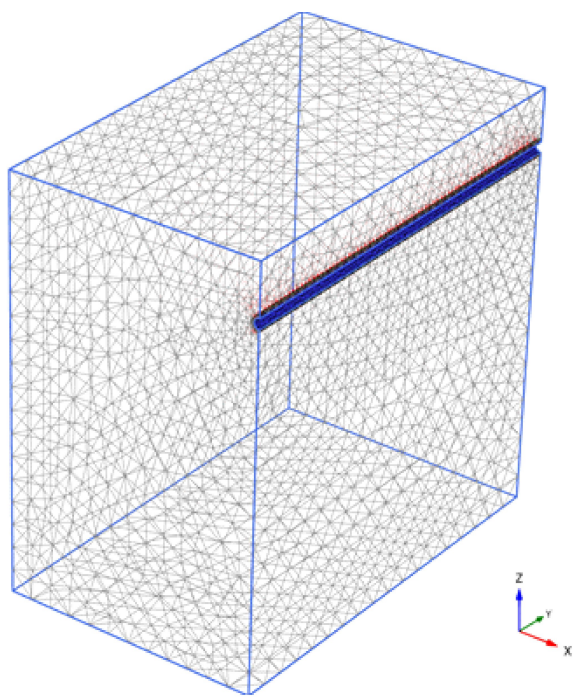

(b)

Fig. 8. Total displacement vectors and flow of soil displacement during the swelling process: (a) empty pipe, (b) pipe under pressure

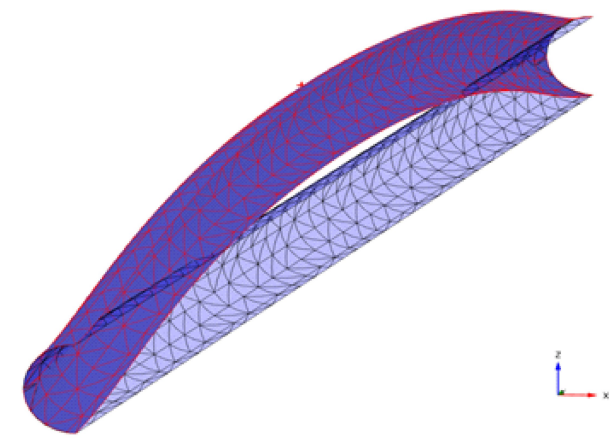

(a)

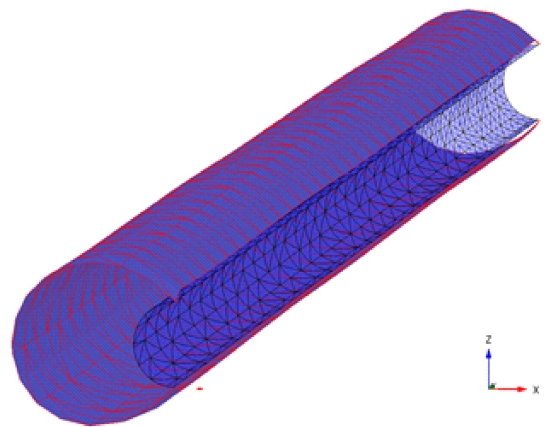

(b)

Fig. 9. Deformed shape of pipeline resulting from the swell of expansive soil: (a) empty pipe, (b) pipe under pressure

The distribution of the pipe internal displacements is presented in Figure 10. It is clearly seen that there is an important upward displacement of an empty pipe buried in a swelling soil and a significant decrease in displacement in the pipe under pressure (Figure 10b). The maximum vertical displacements of the nodes are $12.50 \mathrm{~mm}$ for the empty pipe, occurring in the middle of the pipe, and $0.10 \mathrm{~mm}$ in the pipe under pressure and this is located in the central part of the pipe span.

Figure 11 illustrates the longitudinal variations of the bending moment in the empty pipe and pipe under pressure. It is seen that the maximum bending moment 


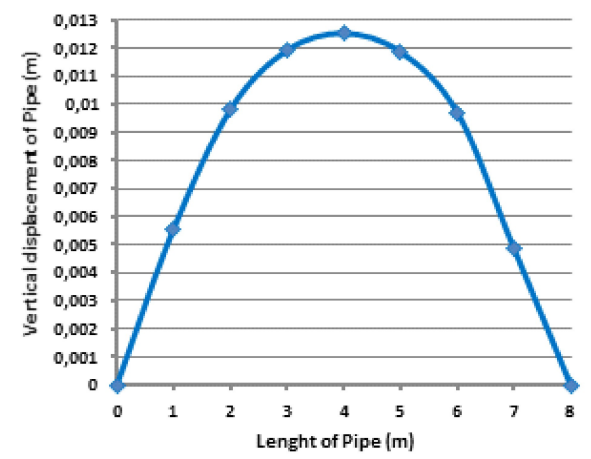

(a)

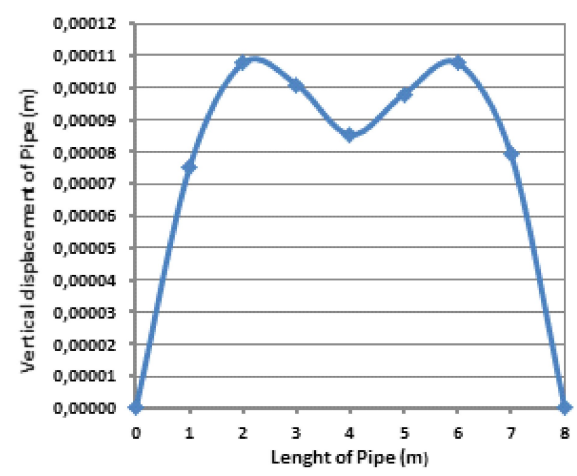

(b)

Fig. 10. Vertical displacement on the pipe: (a) empty pipe, (b) pipe under pressure

for the model pipe under pressure is greater than that obtained by the model of empty pipe by about $44 \%$. The first end is considered a critical section, because the curves reach their maxima there, and these values decrease with distance until reaching minimal values at a distance of $1 \mathrm{~m}$, after which they have very similar values until the other end. The curves illustrate variations in sign according to changes of the stress level which describe the behavior of the pipe by the swelling pressure of the soil and internal pressure. The maximum swelling occurs at the ends of the pipe where the restraint of soil is small.

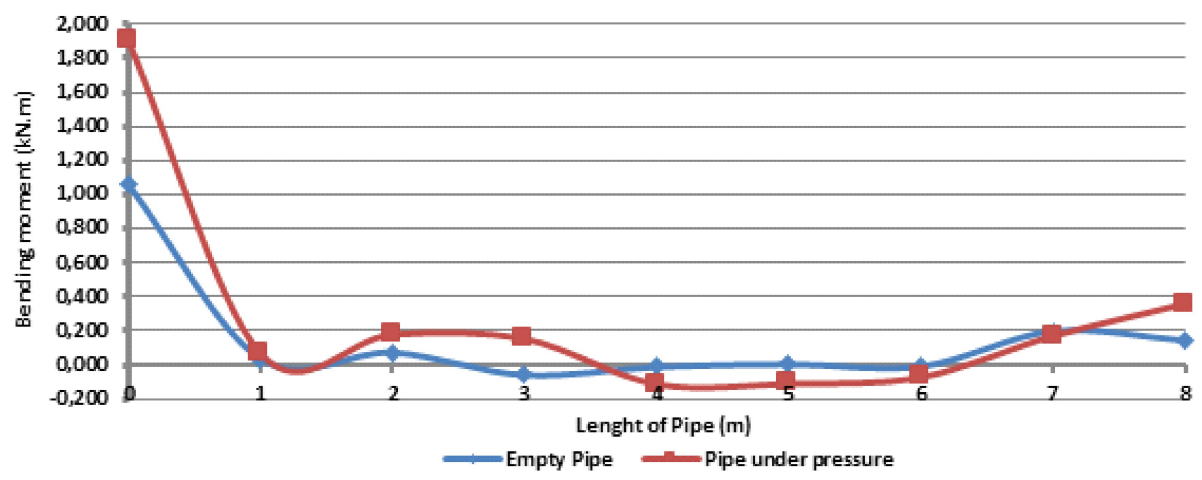

Fig. 11. Variation of bending moments along the length of a pipe

Figure 12 illustrates the distribution of the total vertical stresses in soil $\left(\sigma_{z z}\right)$ below the pipe. It is noted that the vertical stress has maximum values at the ends of the pipe. These stresses decrease between the two ends until they have minimum values at a distance of $1 \mathrm{~m}$, with a change of stress values between them. It can be noticed that the occurrence of the maximum stress on the lower plane of the pressure pipe is greater than that without pressure by about $35 \%$. It can be also seen in the figure that the vertical stress at the first end is greater than that at the other end in the case of 
pipe under internal pressure, while in the case of an empty pipe, the values are very similar at both ends.

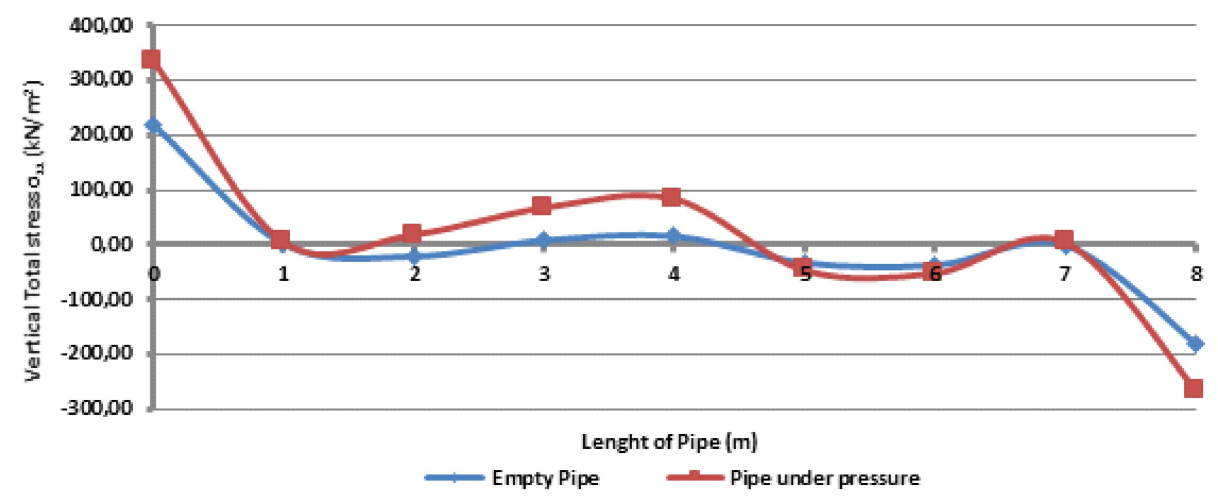

Fig. 12. Distribution of the vertical total stress $\sigma_{z z}$ below the pipe

The differences in bending moments and the total vertical stresses of the soil at the two ends of the pipe are due to different distribution of moisture and the degree of soil saturation, which resulted in an uneven distribution of soil swelling and volume change.

\subsection{Parametric Studies}

\subsubsection{Effect of Burial Depth}

Usually, the pipe-lines are installed at a small burial depth within the soil to maintain the installation and access, works of maintenance and repair. In this simulation, three various values are proposed to investigate the influence of pipe burial depth in the soil; $1 \mathrm{~m}, 2 \mathrm{~m}$ and $3 \mathrm{~m}$.

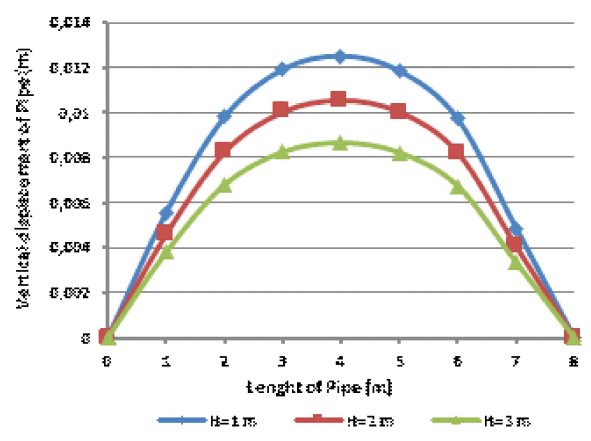

(a)

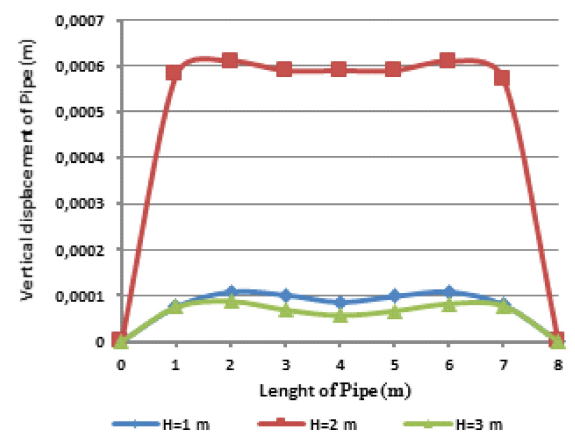

(b)

Fig. 13. Relationships between burial depth and pipe vertical displacement: (a) empty pipe,

(b) pipe under pressure 
Figure 13 presents the vertical displacement distribution along the pipe length as a function of the variation of burial depth. For the empty pipe, it is noticed that the maximum displacement decreases with the depth by $31 \%$ between $H=1 \mathrm{~m}$ and $3 \mathrm{~m}$, and the curves have a similar shape (Figure 13a). Furthermore, the displacement distribution along the pipe is uniform and indicates the same trend. Additionally, the displacements are inversely proportional to depth, contrary to the case of pipe under internal pressure where the vertical displacements increase with the increase in depth of $82 \%$ between $H=1 \mathrm{~m}$ and $2 \mathrm{~m}$, and the decrease is about $85 \%$ between $H=2 \mathrm{~m}$ and $3 \mathrm{~m}$, while the displacement values increase from both two ends until they reach their maximum values at a distance of $2 \mathrm{~m}$, showing a small variance between them, as illustrated in Figure 13b. The curves exhibit similar shape and the displacements distribution is uniform and indicates the same trend. As a summary, the pipe displacement is considerably affected by the burial depth, and the optimal burial depth is $H=3 \mathrm{~m}$.

Fattah et al (2018) observed that a soil-pipe interaction can be initiated by the movement of the soil that acts parallel and horizontally with the pipe longitudinal axis if the pipe axial stiffness permits it to withstand the soil deformation. So that the pipe stiffness in the present study played a considerable role in controlling the movement of the soil around the pipe.

\subsubsection{Effect of Soil Cohesion}

In the problems of soil-pipe interaction, the effect of soil properties on the behavior of pipe depends on many parameters, such as characteristics of the soil, in addition to the properties of the pipe. In our model, the type of soil above the pipe is clayey soil with different cohesion values which were chosen as $20,40,60,80$ and $100 \mathrm{kPa}$ in the analysis.

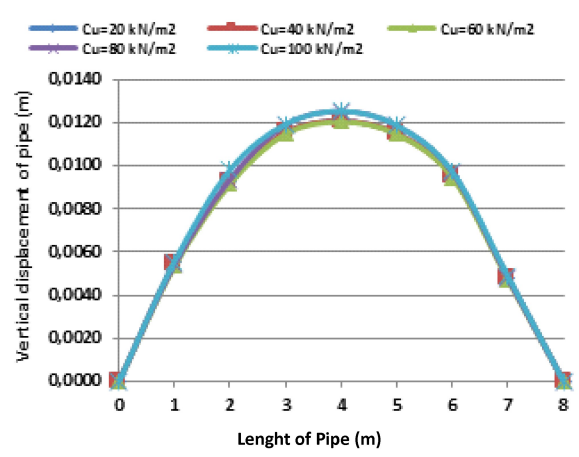

(a)

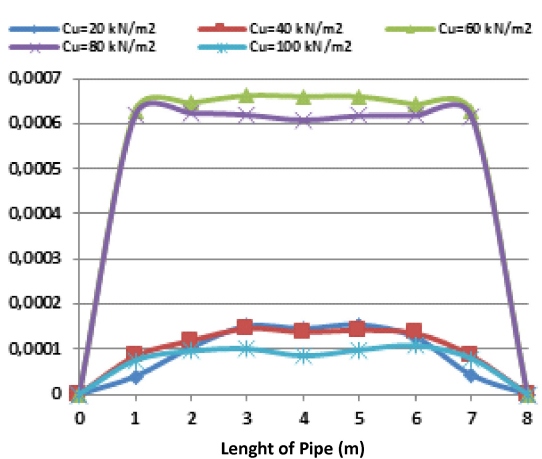

(b)

Fig. 14. Relationships between soil cohesion and pipe vertical displacement: (a) empty pipe, (b) pipe under pressure 
Figure 14 shows the vertical displacement distribution along the pipe length for different cohesion values $C_{u}$. From the curves given in Figure 14a it can be observed that the maximum vertical displacement of the pipe is constant when $C_{u}$ ranges from $20 \mathrm{kPa}$ to $60 \mathrm{kPa}$, respectively, and when the value of $C_{u}$ exceeds $60 \mathrm{kPa}$, the increase in the maximum vertical displacement becomes very small at $4 \%$; this is because of the stiffness of the pipe-soil system. From the results in Figure 14b it can be observed that the increase in cohesion $C_{u}$ increases the vertical displacement of the pipe by $78 \%$ when $C_{u}$ ranges from 20 to $60 \mathrm{kPa}$. Also, when the cohesion $\mathrm{Cu}$ increases from 60 to 80 and $100 \mathrm{kPa}$, the vertical displacement decreased by $6 \%-85 \%$, respectively. Also, it is obvious that the presence of pressure inside the buried pipe has an effect on the pipe-soil system, resulting in a decrease in the vertical displacement compared to the empty pipe.

\subsection{Comparison of the Numerical Modeling Results with Laboratory Results}

The finite-element numerical modeling results were compared with observations from a laboratory model constructed at Queensland University of Technology, Brisbane, Australia, with experiments conducted on a two-meter long polyethylene pipe buried in a box filled with reactive clay soil collected from the area of Merri Creek in Victoria, Australia (Gallage et al 2012). It was found that the laboratory model did not consider the internal pressure of the pipe and the greater burial depth of the pipe, where these two factors provide higher resistance to the pipe and reduce its upward deflection, and this was proven by the numerical modeling of the recent model.

\section{Conclusions}

The results of the numerical simulations of the buried pipe in swelling soil analyzed by the finite element method allowed us to formulate the following conclusions:

1. The numerical method provides useful information on the mechanism of deformation of buried pipes, proving that the deformation is related directly to the pipe and soil properties.

2. When a comparison is made with laboratory models, it was found that the latter model cannot account for the internal pressure in the pipe or the greater depth of its burial, where these two factors provide higher resistance to the pipe and reduce the upward deflection. The finite element simulation have shown that the presence of fluid pressure inside the buried pipe results in a decrease in the maximum swelling of the soil by about $95 \%$.

3. The pipe displacement is considerably affected by the burial depth of a pipe.

4. The vertical stress at the one end of the pipe is greater than that at the other end in the case of a pipe under internal pressure, while in the case of empty pipe, the values are very similar at both ends.

5. The results of the numerical simulations have indicated that the interior pipe pressure causes a decrease in the pipe vertical displacement. 
6. The increase of the soil cohesion (ranges from $60 \mathrm{kPa}$ to $100 \mathrm{kPa}$ ) decreases the deflection of the pipe under pressure. This is because of the increase in the strength of soil and in the relative stiffness of the pipe-soil system. In contrast, the maximum displacement in the empty pipe appears to be more moderate.

\section{References}

Al-Rawas A. A., Goosen M. F. A. (2006) Expansive Soils, Taylor and Francis, London, New York. Bjerrum L., Eide O. (1956) Stability of strutted excavations in clay, Géotechnique, 6 (1), 115-28.

Cheuk C., Take W., Bolton M., Oliveira J. (2007) Soil restraint on buckling oil and gas pipelines buried in lumpy clay fill, Engineering structures, 29, 973-982.

Davie J. R., Sutherland H. B. (1977) Uplift resistance of cohesive soils, Journal of the Geotechnical Engineering Division, ASCE, 103 (9), 935-52.

Derriche Z., Iguechtal L., Tas M. (1999) Comportement des ouvrages dans les argiles expansives d'In-Aménas, French Journal of Geotechnics, 89, 55-65.

Djedid A., Bekkouche A., Aissa Mamoune S.M. (2001) Identification et prévision du gonflement de quelques sols de la région de Tlemcen (Algérie), Bulletin des laboratoires des ponts et chaussées, 233, 67-75.

Eiksund G., Langø H., Øiseth E. (2013) Full-scale test of uplift resistance of trenched pipes, International Journal of Offshore and Polar Engineering, 23 (4), 298-306.

Fattah M. Y., Salim N. M., Irshayyid E. J. (2017) Influence of soil suction on swelling pressure of bentonite-sand mixtures, European Journal of Environmental and Civil Engineering, https://doi.org/10.1080/19648189.2017.1320236, Taylor \& Francis.

Fattah M. Y., Hassan W. H., Rasheed S. E. (2018) Effect of geocell reinforcement above buried pipes on surface settlement, International Review of Civil Engineering (I.RE.C.E.), 9 (2), 86-90.

Gallage C., Chan D., Kodikara J. (2012) Response of a plastic pipe buried in expansive clay, ICE Proceedings Geotechnical Engineering, 165 (1), 45-57, DOI: 10.1680/geng.12.00086.

Gould S., Boulaire F., Kodikara J. (2009) Understanding how the Australian climate can affect pipe failure, Proceedings of $\mathrm{Oz}$ Water 09.AWA, Melbourne, Australia.

Gould, S. (2011), A study of the failure of buried reticulation pipes in reactive soils, Ph.D. Dissertation, Australia, Civil Engineering, Monash University.

Hachichi A., Fleureau J. M. (1999) Caractérisation et stabilisation de quelques sols gonflants d'Algérie, French Journal of Geotechnics, 86, 37-51.

Kassiff G., Zeitlen J. G. (1962) Behavior of pipes buried in expansive clay, Journal of the Soil Mechanics and Foundations Division, ASCE, 88, 132-148.

Makar J. M., Desnoyers R., McDonald S. E. (2001) Failure modes and mechanisms in gray cast iron pipe, Ontario, Canada, 1-10.

Maltby T. C., Calladine C. R. (1995) An investigation into upheaval buckling of buried pipelines - II Theory and analysis of experimental observations, Int. J. Mech. Sci, 37 (9), 965-983.

Martin C. M., White D. J. (2012) Limit analysis of the undrained bearing capacity of offshore pipelines, Géotechnique 62 (9), 847-863.

McGrath T. J. (1998) Pipe-soil interactions during backfill placement, Ph.D. Thesis, University of Massachusetts, Amherst, MA.

Ng C. W. W., Springman S. M. (1994) Uplift resistance of buried pipelines in granular materials, Proc. Centrifuge 94, Singapore, 753-758.

Pettibone C. H., Howard A. K. (1976) Distribution of soil pressures on concrete pipe, Journal of Pipeline Division, ASCE, 93 (2), 85-102. 
Philipponat G. (1991) Retrait-gonflement des argiles, proposition de méthodologie, French Journal of Geotechnics, 57, 5-22.

Potter J. C. (1985) Effects of vehicles on buried high pressure pipe, Journal of Transportation Engineering, 111 (3), 224-235.

Rajani B., Zhan C., Kuraoka S. (1996) Pipe-soil interaction analysis of jointed water mains, Canadian Geotech J., 33 (3), 393-404.

Rajeev, P., Kodikara J. (2011) Numerical analysis of an experimental pipe buried in swelling soil, Computers and Geotechnics, 38, 897-904.

Randolph M. F., Houlsby G. T. (1984) The limiting pressure on a circular pile loaded laterally in cohesive soil, Geotechnic, 34 (4), 613-623.

Rjeily Y. E. A., Khouri M. F. (2014) Longitudinal stress analysis of buried pipes under expansive soils, International Journal of Science and Research (IJSR), bf 3 (11), 2593-2599.

Sargand S. M., Hazen G. A. (1998) Field verification of standard installation direct method for concrete pipe, Ohio Research Institute for Transportation and the Environment.

Schaminée P. E. L., Zorn N. F., Schotman G. J. M. (1990) Soil response for pipeline upheaval buckling analysis: Full scale laboratory tests and modelling, Offshore Technology Conference, Houston, OTC $6486563-572$.

Shumulevich I., Galili N., Foux A. (1985) Soil stress distribution around buried pipes, Journal of Transportation Engineering, 112 (5), 481-493.

Trautman C. H., O’Rourke T. D., Kulhawy F. H. (1985) Uplift force-displacement response of buried pipe, Journal of Geotechnical Eng. Division, ASCE, 111 (9), 1061-1075.

Vandangeon P. (1992) Exemples de sinistres en région parisienne, French Journal of Geotechnics, 58, 7-14.

Vu H. Q. (2002) Uncoupled and coupled solutions of volume change problems in expansive soils, Doctoral thesis, Dept Civil Engineering, University of Saskatchewan.

Wang, J., Haigh S. K., Thusyanthan N. I. (2009) Uplift resistance of buried pipelines in blocky clay backfill, Proc. International Offshore (Ocean) and Polar Engineering Conference, ISOPE 2009 TPC 564.

WSAA (2008) Australian Urban Water Industry, Water Services Association of Australia, Report card $2007 / 2008$. 